\title{
ADMISSIBILITY OF A VIDEO AS EVIDENCE IN A COURT: ITS PRESENTATION AND PROBATIVE VALUE
}

\author{
Dr.Muhammad Arif Rajput ${ }^{1}$ \\ Assistant Session Judge, Sujawal (Thatta), Sindh \\ Resource Person at Sindh Judicial Academy, Karachi \\ Email: drarifrajput1@gmail.com
}

\begin{abstract}
To general public, all videos are perceived to be true, but they may not have probative value in the Court of law. The undertaken article analyzes the admissibility and probative value of a video presented as evidence before a court in the Criminal Justice System of Pakistan (CJSP). It analyzes the relevant law and diagnoses the problems with the video evidence through the lens of the judgments of Superior Courts. The court of law objectively ascertains that a video presented as evidentiary means bears significant relevance to the fact in question. It must be admissible under the law, and it must be proved to be genuine. To fill up the gap between a "Video" and a "Video Evidence", there is a process, which is known as video authentication. It determines that the video contents are genuine, authentic, credible, unaltered, untampered and unfabricated. The study discusses various modes of video authentication. Precedents set by superior courts of Pakistan show that convictions have been made once the courts are satisfied with the credibility of video evidence. In the court of law, video evidence is normally presented after the completion of prosecution evidence. The video is played in court and is watched by the presence. But the researcher establishes that such process does not have legal justification. The article suggests that it would be legal and proper for the prosecution to produce the video evidence through the witness, during his evidence, who is either victim, witness, recorded and/or copied the video directly from original source such as C.C.T.V system and that witness would be subjected to cross examination.
\end{abstract}

Keywords: Video, Evidence, Credibility, authentication, Criminal Justice System of Pakistan.

\section{INTRODUCTION}

Use of smart phones and CCTV system (closed-circuit television) for recording videos of the events happening around has

${ }^{1}$ I am thankful to Mr. Muhammad Riaz Rajput, District and Sessions Judge (Retd.) for the critical analysis and suggestions for improving this paper. The author can be approached at: drarifrajput1@gmail.com 
drastically increased. In Pakistan, total mobile phone users on May, 2020 were 166 Millions, while the number of 3G/4G subscribers reached to 80 million (Telecom indicator P.T.A, 2020). Likewise, now-a-days, we find CCTV cameras installed at the important offices and places, traffic signals, houses etc. These mobile phones, CCTV cameras and other video recording devices such as car dashboard camera and cop-cams have enabled millions of people to record, save and share the videos that could be used as evidence in the courts of law. Thus, the availability of these devices has become a great source of video evidence. There can be no second opinion that a video as evidence may play a key role for solving a crime by investigating agencies and proving an accused guilty or innocent before the court of law. Given to its distinctive feature, video evidence is different from the other type of evidence because it provides an eye-witness account of happening of events. For instance, a CCTV camera records the incident of robbery from an ATM of a bank or a car dashboard camera records an event of an accident. By producing a video as evidence in a court, conventional eye-witness testimony can be corroborated to a great extent. The other advantage of video is that due to advanced techniques for identification and comparison of the human face such as facial imaging, the investigating agencies have become more equipped to identify the culprits as well as to identify the witnesses available there. Sometimes, the identification of witnesses is required for the reason that despite their presence at the place of occurrence, the witnesses do not come forward to testify for various reasons such as fear, lack of trust in the police, or to avoid inconvenience of appearing before courts.

Given to the exponential growth in the number of smart phone users, the social media has attained the status of an important platform for communication, news and information. People may share anything on the social media without verifying it. It would be difficult, if not impossible, for a common man to determine the genuineness of a video obtained from such a source. As a result, such videos on the social media may prove to be more dangerous because of their influence and impact on the masses. Generally, people, by merely watching a video on the social media or other source, perceive it to be genuine and true, without verifying its genuineness and/or original source. Moreover, the public also expect courts to consider such 
videos as evidence and treat them as factual and true in the same manner as they do. What the people think may be sufficient to persuade them of the existence or non existence of something, but it must be kept in mind that it is prerequisite and standard in a criminal case that evidence presented therein must be "beyond any reasonable doubt". However, any doubt about the genuineness of the video lessens its credibility. This is the reason that when any video is sought to be produced in a court, it unleashes a series of questions: firstly, whether the video is admissible as evidence in the court or not? Secondly, what should be the procedure for producing it as evidence in a court? Thirdly, whether the video is credible to the extent to base conviction on it?.

\section{SCOPE OF THE STUDY}

The study aims to determine the admissibility of video evidence in court of law. And if admissible, ascertaining the probative value thereof by exploring the avenues to authenticate a video for making it a reliable piece of evidence for basing the conviction in CJSP. A special focus is made on the modus operandi to produce video evidence before a court of law.

\section{OBJECTIVES OF THE STUDY}

This study aims to dichotomize the approaches of a common man and a court of law in giving probative value to a video as evidence in the CJSP. This study also analyzes how to redress the problems attached with video evidence in its admissibility, credibility and the mode and manner of proving it before a court of law.

\section{RESEARCH METHODOLOGY}

The methodology of the research is based on "doctrinal legal research". The study of existing statutory provisions and the systematic analysis of the case laws on the subject have been done through legal reasoning. In this study, a descriptive method has been adopted for the purpose of getting a clear picture of the current situation of the phenomenon. The diagnostic approach has been followed to fill the gap between a "video" and "video evidence". To ascertain the anomaly existing in the law to accommodate and give due probative value to the video evidence, precedents of the 
Honourable Supreme Court of Pakistan and Honourable High Courts, have also been analyzed. These case laws are also employed as a source of information to diagnose the problem. For this article, both primary (statute) and secondary data in the form of books, articles, case-laws, reports and journals have been analyzed to explore the issue in hand.

\section{ADMISSIBILITY OF THE VIDEO EVIDENCE}

The CJSP is adversarial, casting primary responsibility on the prosecution "to prove charge against the accused beyond any reasonable doubt", who would confront indictment under a presumption of innocence (Ejaz v. The State, 2017). In CJSP, the previous decisions of superior courts are binding precedents upon the sub-ordinate courts under the doctrine of stare decisis (Articles 189, 201, 203GG of Constitution).

The CJSP has entered a new era of the technology based evidence or forensic evidence. The forensic evidence is a type of evidence which is obtained through the application of forensic science and technology such as digital evidence, ballistics, DNA (Deoxyribonucleic Acid) etc. (Forensic evidence, PPts). A piece of information stored electronically is termed as the digital evidence and it "can be used as evidence in any legal proceedings" (Tubrazy, 2015). A video is also stored and transmitted in digital form; therefore, it is regarded as one of the kinds of digital evidence. As to the admissibility of video as evidence in other jurisdictions, the High Court of Sindh, in the case of Sikandar Ali Lashari v. The State (2016), has observed that the video evidence has been admitted in English courts, mainly in criminal cases.

The critical analysis and evaluation of the admissibility of video evidence in the CJSP shows that Article 164 of Qanun-e-Shahadat Order, 1984 (Q.S.O), confers discretion upon the courts to allow production of "evidence that may have become available because of modern devices and techniques". This Article has revolutionized the scope to accommodate evidence generated through modern innovative devices and/or techniques. It has invested the courts with a wide discretion to consider recorded evidence obtained through visual, audio, digital, sonic or biological and other means, which is capable to establish or negate any fact-in-issue. This article has left the admissibility of video evidence at the discretion of a court. 
Moreover, by adding proviso to the Article 164 of Q.S.O, through Act IV of 2017 dated 16.02.2017, it has been made clear that "the conviction based on the evidence obtained through modern devices or techniques may be lawful".

The next question regarding the video evidence, which needs to be addressed, is about the procedure of producing the report of forensic expert concerning the video in a court. In criminal trials, section 510 of Code of Criminal Procedure, 1898 (Cr.P.C) speaks of the production of certain reports of experts. Under this section, certain reports of the expert i.e. ballistic expert report, chemical examiner report, serologist report and fingerprint expert report have been made admissible as evidence. In case of production of these reports in a criminal trial, summoning and examining the expert for his evidence is not mandatory for the reason that these reports of experts are treated as evidence of their own contents (Muhammad Shahid Sahil v. The State, 2010). However, the discretion has been given to courts to examine any such forensic expert, who prepared such report, if the court considers it necessary for dispensing justice. This section, however, is not exhaustive for the reason that the reports of experts, who have not been referred in this section specifically, would not be admissible, without summoning and examining the expert as witness in the court. For instance, the reports of digital forensic expert or report of D.N.A profiling are not mentioned in this section. In this connection, it is profound to examine the Article 59 of Q.S.O. Now, prior to dilating upon this provision, it is pertinent to mention here that in the legal proceedings, it is a general rule of evidence that the witness can depose the facts only in his evidence (Hanif v. State, 1992). However, this general rule has some exceptions, which make the opinion of expert admissible in evidence (Murphy, P., 2003). Article 59 of Q.S.O provides one of such exceptions, which makes the opinion of expert admissible. According to this article, the opinion of experts "upon the point of foreign law, of science, or art, or as to identity of handwriting or finger impressions, etc." has been made relevant (Khan, F. A., 2015).

Keeping in view the afore-made discussion, the combined review of section 510 Cr.P.C. and Article 59 of Q.S.O. would show that the report of digital forensic expert in respect of video evidence cannot be produced, in evidence, without summoning and examining the forensic 
expert as witness in the court. To further simplify it, the above provisions of law requires that if the report of expert on video evidence is sought to be produced in a trial then it is necessary to call and examine the expert as a witness in the court. The legislature, however, were cognizant of this anomaly in the scheme of law in accommodating such advanced type of forensic evidence. The legislature therefore, by virtue of section sub-section (3) of section 10 of the Sindh Forensic Science Agency Act, 2017 (SFSAA), subsection (3) of section 9 of the Punjab Forensic Science Agency Act, 2007 (PFSAA), sub-section (3) of section 8 of the Balochistan Forensic Science Agency Act, 2015 (BFSAA) and sub-section (3) of section 9 of the Khyber Pakhtunkhwa Forensic Science Agency Act, 2020 (KPFSAA), has extended the applicability of section 510 Cr.P.C. to all those experts, who are appointed in the agency, specially skilled in a forensic material under Article 59 of Q.S.O. These enactments have enabled the courts to allow the production of reports of those forensic experts, appointed in the concerned forensic agency, who prepare the report and have not been specifically referred in section 510 Cr.P.C., in the same manner as provided therein. Thus, "a forensic report prepared by an analyst of the Forensic Science Agency with respect to a video is per-se admissible as evidence under section 510 Cr.P.C." (Ishtiaq Ahmed Mirza v. Federation of Pakistan, 2019).

\section{CREDIBILITY OF THE VIDEO EVIDENCE}

In the present digital age, the sharing of audio-video footages has become very easy because of the social media. No doubt, audio-video recordings can be altered, tampered, edited or superimposed easily and seamlessly with multimedia tools, but at the same time the perception that a video, being easily alterable, is not credible is also unjustifiable. Raising doubts over the credibility of a video, due to its fragile nature, would not justify keeping it out from the legal proceedings for the reason that the credibility and genuineness of a video may be determined through the process of "video authentication". This process may be divided into two main types namely "witness authentication" and "technological authentication" (Gregory et.al., 2005). As the name suggests, the witness authentication can be done through the witness who is acquainted with the contents of a video. This may includes the person, who has recorded the video, or the person who prepared the copy from the original source such as CCTV system or the person 
who, at the time of recording video or happening of an event, was present there. In some circumstances, witness authentication may not be possible or requires further verification of genuineness of video. In such circumstances, the forensic process is employed for determining the credibility and genuineness of a video, which is known as technological authentication. This process confirms as to whether given video has been tampered with or not and if it is tampered with, then to show where such tampering has occurred, proving the nature of tampering (Upadhyay, 2011).

No doubt, the satisfaction of court as to the credibility of video evidence is a challenging issue. However, video authentication, as described above, can objectively establish that a video, being sought to be produced as evidence in a court, is credible or otherwise. Additionally, it is essential to determine that how the video has been acquired and preserved (Gregory et al., 2005). According to Tubrazy (2015), "the procedure of preserving of the video evidence must be to the extent that any third party may be able to come to the same conclusion if it applies the same process." It is noteworthy that same rules and laws which are applicable to documentary evidence are equally applicable to video evidence (Muhammad Sohail v. The State, 2019); therefore, there must be painstaking documentation for the appropriate collection; retrieving and chain of custody of a video evidence (National Forensic Science Technology Center®). To sum up the above, if a video is authenticated by the authentication process, as discussed above, or by any other mode verifying that since its recording till its production before the court, it has not been altered and manipulated, then it would be a reliable evidence to establish guilt or innocence of the accused, as the case may be.

\section{CONVICTION ON THE BASIS OF VIDEO EVIDENCE}

The analysis of the case-laws of the Honourable Apex Court of Pakistan and of the High Court's show that in the CJSP, if the courts are satisfied that the video evidence is credible and authenticated, the convictions can be based upon it. In furtherance to it, proviso to the Article 164 of Q.S.O has also made it clear that a conviction based on forensic evidence may be lawful". In the cases of Shakeel $v$. The State (2010), Bakht Munir v. The State (2014), Shahid Zafar v. The State (2014) and Syeda Waheeda Shah v. E.C.P (2013), the convictions, mainly based on video evidence, recorded by the trial 
Courts have been maintained by superior courts. Recently, in the case of Sikandar Ali Lashari and others v. The State, in Special Cr. A.T. Appeal No.261, 262, and 311 of 2018 and Conf. Case (A.T.A) No.13 of 2018, the honourable High Court of Sindh has maintained the conviction recorded by the Anti-Terrorism Court Karachi, which was mainly based on audio-video evidence and other circumstantial evidence, vide judgment dated 20-04-2020.

However, the Honourable Supreme Court of Pakistan, in the case of Ishtiaq Ahmed Mirza v. Federation of Pakistan (2019) has ruled that a court cannot rely upon a video evidence until the same is proved to be genuine and unmanipulated. This means that when the courts are not satisfied with the credibility of video evidence, then it shall not be relied upon for the safe administration of justice. In the case of $K h$. Ijaz Ahmad v. D.R.O. (2001), Returning Officer (R.O.) relied upon video wherein, the candidate was shown to be attending a dance party in which, he was showering money on the dancing girl. Such video film was seen in isolation by R.O. and nomination of the candidate was rejected on the basis of such evidence. However, High Court set aside the order of R.O on the ground that neither the person, who had recorded the video, was produced before the R.O nor any affidavit of said person was produced therefore, said video cannot be considered as a piece of legal evidence. In the cases of Asfandyar v. Kamran (2016) and Ammar Yasir Ali v. The State (2013), the courts have observed that "mere production of C.C.T.V footage/video evidence, as a piece of evidence, in the court is not sufficient to rely upon the same, unless it is proved to be genuine". In the case of Moaz Waqar v. The State (2019), the person who recorded CCTV footage or copied it in USB from system were not produced in trial which, according to court, was necessary evidence to be corroborated therefore, video evidence was not considered as valid piece of evidence. In these cases, the issue of credibility of the video as evidence has been discussed and it was observed that "video cannot be relied upon unless corroborated and proved to be genuine;" as a result, said videos were not deemed as a credible means of evidence.

A critical analysis of the above cases unfolds that the courts have suggested only one mode of video-authentication, which is the witness authentication, by recording of evidence of a person, who has captured video footage or the person, who copied the video directly from the 
original source such as CCTV system. However, in some cases, it may not be possible. There may be cases where the video of the event had been recorded by the accused and secured on his instance. There may be possibility that the person who recorded the video is untraceable or died. In such cases, the mode of authentication, as suggested in above cases, would not be possible. In this context, the case of Yasir Ayyaz v. The State (2019) is crucial. The facts of the said case are that the victim "S", who left home to fetch milk, was taken by the accused "Q" to nearby bushes and was raped by "Q"; thereafter, the accused also called the co-accused "B" and " $Y$ " to join the carnal assault. The accused " $Q$ " also recorded the assault on a cell phone camera, and the victim was let go with the threat of the disclosure of the video. After a few days, the accused once again desired the victim to oblige them and this finally compelled the victim to take her father into confidence, who got registered the F.I.R on the same day. During investigation, the mobile phones were recovered from the possession of accused persons, while the complainant handed over the police a memory card containing the video of the assault, which were then sent to a forensic agency for the expert opinion. Consequently, the report received from the expert confirmed integrity of the video footage to the effect that "no editing features were observed in the contents of the visuals in the video clip named "imajm.avi'". In this case, the trial court, after satisfying itself with the credibility of video evidence through the technological authentication process by a forensic expert, convicted the perpetrators of this heinous crime. Said decision of trial court was upheld, in appeal, by the Honourable High Court. In the case of Ishtiaq Ahmed Mirza $v$. Federation of Pakistan, (2019), the Honourable Apex court has observed that the advancement of science and technology has made it possible to forensically examine the genuineness of a video. This forensic examination can also amply ascertain whether the video has been manipulated, superimposed, altered, edited or not. Therefore, without forensic examination of a video, it is unsafe for a court to consider it as a credible piece of evidence. Thus, it has been made mandatory for the courts to insist for the video authentication through both modes viz. witness authentication, as well as, technological authentication, to exclude the chances of manipulation or tempering with the video evidence. 


\section{PRESENTING THE VIDEO EVIDENCE IN A COURT}

Generally, it is a perception of public that at any stage of a trial of criminal case, a complainant or any other person may presents a video, either in a USB, CD or any other storage device, with the expectation that trial judge should watch and believe it. However, in the CJSP, this may not be allowed for various reasons. To begin with, it is noteworthy that the right to fair trial is an inalienable and fundamental right of a person (Articles 4 and 10-A of the Constitution). This right has been embodied in the CJSP. In a criminal trial, section 265-C (Sessions Trial) / 241-A Cr.P.C (Magistrate Trial) relates to the supply of statements and documents to the accused. The niceties of this section articulates that copies of the documents are to be supplied free of cost to the accused at least seven days prior to commencement of the trial. The object to supply of copy of documents under this section is to let accused know the nature of the case registered against him and confront the witnesses during the evidence which is to be recorded. Now coming to the status of the video footage, it has been held, in the case of Sikandar Ali Lashari v. The State (2016), that in view of section 29 of Pakistan Penal Code (P.P.C) and clause (b) of Article 2 of Q.S.O, the video footage saved on C.D, U.S.B or any other storage devices, sought to be produced at trial, falls under the definition of a document. Hence, if the prosecution or complainant relies upon video evidence then, before the charge is framed, it would be statutory right of the accused to get the copy of it, so that he may know the prosecution case, before he is sent up to stand for trial. Further, merely watching a video by a judge may prejudice him and considering such video as evidence would not meet the ends of justice. Moreover, presenting a video in the mid of a trial would get the accused surprised and he would be deprived of his right to defend.

There is another significant issue connected with the video evidence, which needs to be attended, is the unnecessary examination of large number of witnesses by the prosecution in a criminal trial. In a case, wherein it has been verified /authenticated by the forensic expert that the video proposed to be produced in court is genuine; the prosecution unnecessary examines large number of witnesses in a case. One of the examples of such cases is Sarfraz Shah Murder case, wherein evidence of twenty witnesses were got recorded by the prosecution. This case had caught the attention of public in the year, 2011 when a video of an unfortunate incident has gone viral on social media, wherein it was shown that a teenager namely Sarfraz Shah was being shot by Rangers personnel in a park of Clifton, Karachi. The 
victim, in injured condition, beseeched the Rangers Personnel for his shifting to hospital but he was left lying there due to which, he died. During the trial of said case, the expert had reported that the video showing the incident was genuine and without any manipulation. Said video footage of the incident was recorded by a cameraman of T.V channel. In his evidence, said cameraman stated that Rangers personnel pushed the victim Sarfraz Shah and one of them fired two shots at him, as a result he fell down and started bleeding. This cameraman identified the accused present in the court and also affirmed that the video clip of the unfortunate incident was the same which he had recorded. The Anti-Terrorism Court, Karachi convicted the accused persons. The Honourable High Court of Sindh has upheld said conviction of accused persons, which was further maintained by the Honourable Supreme Court of Pakistan, with some modification (Shahid Zafar v. The State, 2014). It is noteworthy that in appreciation of evidence, the quality of the evidence and not the quantity of the evidence has a bearing on the fate of the case of the prosecution; such is the guideline given in the case of Haq Nawaz v. The State (2000) by Honourable Supreme Court of Pakistan. The point which deduced from this principle is that in a criminal trial, neither evidence of number of witnesses shall stamp the genuineness of an occurrence nor evidence of a single witness be discarded only on the ground that the same had been not corroborated by other witness. Even in a murder case, conviction can be recorded on the evidence of a single witness, if court is satisfied that he is reliable (Niaz-Ud-Din v. The State, 2011). In the Sarfraz Shah Murder case, it has been noted that the video authentication was done through both modes as described above i-e witness authentication and technological authentication. Even then, 20 witnesses were examined in that case by the prosecution.

Thus, keeping in view the above bench mark, it may be concluded that in a case, where the video evidence has been proved as genuine then the examination of large number of witnesses may not change the fate of case rather it may have certain drawbacks. The first and foremost drawback is that it would cause unnecessary delay in conclusion of trial, which is unfair to victim of crime and/or his family, witnesses as well as to the accused. Secondly; in allowing number of witnesses to narrate the entire incident in their evidence, which has been recorded in a video, it must be kept in view that human memories do not retain photographic picture. It cannot be expected that an eyewitness, who was present on the spot or who has recorded 
the video of the incident, would narrate the incident, in his evidence, in a video playback manner and to recall the minute details of the incident. They can only remember the main purport of the incident. This may result in disparity in the deposition of such witnesses, due to which, the accused may get benefit of it.

The manner and stage of playing video in a court is another issue, which required to be explored in the light of statutory provisions and precedents. In a trial of criminal case, the normal procedure, prevailing in the courts of law, is that after the closure of prosecution evidence, the video produced by the prosecution as evidence, is watched in the court. An analysis of this procedure would show that there is no logic in it. The evidence of prosecution has already been completed, when the video was being played in court. This procedure has certain drawbacks and does not fulfill the legal requirements. For instance, after playing the video in a court, at the completion of prosecution evidence, if the accused raises any objection on it, then what would be its consequence?. Whether the court would recall the prosecution witness already examined to provide opportunity to prosecution or defence to re-examine and/or cross-examine them?. The fact, however, is that the cross-examination of a prosecution witness is legal basic right of the accused (Sher Zaman v. The State (2007). However, in this procedure, the accused may be deprived from this right of not being provided with an opportunity for cross examining the prosecution witness on video evidence. Thus, there appears to be no legal justification in playing the video at the closure of prosecution evidence. The question of legality of this procedure has come up for consideration before the High Court of Sindh in a case of Sikandar Ali Lashari v. The State (2016), and after discussing its different aspects, the Honourable High Court has disapproved it.

Keeping in view our legislative framework and to meet the ends of justice, it would be legal and proper to produce the video evidence at an early stage of the trial, through the witness, who is either victim and/or witness of the event recorded in the video, and the person who either captured the said video or copied the video directly from CCTV system and that witness should be allowed to be subjected to the cross examination.

\section{CONCLUSION}

The analysis of the statutory provisions of law and case-laws of the Superior courts of the country shows that in CJSP, video evidence is admissible piece of evidence. However, the probative value of the 
video evidence, due to its fragile nature, is dependent upon various factors therefore, it cannot be expected from the court of law to blindly rely upon it. The court has to weigh it like any other kind of evidence. Besides, being relevant to fact-in-issue, it must be proved before the court that video is credible and has not been tempered with. This credibility and genuineness of the video can be ascertained by the video-authentication process, as described above. Under the law, there is prescribed procedure for a trial of a criminal case and the mode and manner of producing any evidence. The video evidence is not an exception to it and is being treated as documentary evidence. The study further shows that after the introduction of Forensic Science Agency Acts, by the respective provinces, the forensic expert report on video evidence can be tendered in evidence, as provided under section 510 Cr.P.C, with the exemption to summon and examine the expert in the court. However, discretion has been given to court to summon and examine the expert if the court finds it necessary for dispensing justice. In this study, the problems attached with the video evidence in court including; its credibility, authentication process and mode and manner of its presentation in court, have been analyzed and attempt has been made to resolve and streamline it within the four corners of law by articulating the following recommendations:

\section{RECOMMENDATION}

- If any person desires to produce a video, as evidence, which has not been produced by the prosecution, then he has to file such application before the court.

- The video as evidence must be relevant to controversy involved in the matter and otherwise admissible under the law. It must also be clearly audible and/or viewable. The audio recorded and/or the persons seen in video must be clearly identifiable.

- In view of section 265-C, Cr.P.C. (Sessions Trial) and section 241A Cr.P.C. (Magistrate trial), prior to the framing of charge, the copy of a video sought to be produced as evidence and/or report of forensic science laboratory in respect of such video must be provided to the accused like the copies of other documentary evidence. It is mandatory for the safe dispensation of justice. Moreover, it is also constitutional right of the accused to provide him a fair opportunity to defend himself/herself (Nazim Ali v. Additional Sessions Judge, 2016). 
- To exclude any possibility of tampering with the video evidence and to verify its authenticity the following means of authentication may be adhered to:

- Witness authentication by the witness acquainted with the contents of a video. The video as evidence must be produced through the person who recorded the video. But, if he is not traceable, any other person who was present there and had witnessed the act of recording of the video or occurrence of the event may also record his evidence in corroboration of the events shown in the video. The video may be produced as evidence through the person who had prepared/copied the video directly from the original source such as CCTV system. The voice recorded and/or the individual seen in the video must be identified either by the person who recorded the video or by any other person, who can identify such voice or individual.

- Technological Authentication by the Digital forensic expert.

- If video is authenticated, as referred above, then the video may be produced, in evidence, by the witness, which would be played in the court. It is suggested that this witness would be required to depose that the video, played in the court, is no more or less than the one when recorded. In these situations, an eyewitness can simply identify that the events shown in the video are what he or she recalls actually happened and also affirms that the video is the 'true' record of the events shown. Such evidence should be treated as substantive part of his/her evidence. Then the defence should be allowed to cross examine him/her. This would save the witness (s) from unnecessary botheration and saves the time of all stake holders.

- In some circumstances, it may not be possible to have video authentication by an eyewitness. For instance, if there is no eyewitness to an incident, that may be possible in recordings of the incidents by a CCTV camera, where the maker of the video remains untraced, and/or the accused does not admit the events recorded in the video. In such circumstances, the forensic expert or investigation officer or any other person who has properly retrieved and safeguarded the video may be examined to exclude the allegations of tempering with the video. In such evidence, the source where from the video has been made available and the date 
of acquiring have to be disclosed by the witness to prove that the produced video is unedited or unaltered and accurate. Besides, the chain of the custody of the video from its recording/acquiring till its production before the court must also be proved with painstaking documentation.

- A video, if presented as a means of evidence, should be produced at an early stage of the judicial proceedings, because its production at a later stage may be looked at with suspicion. However, it is not necessary for the prosecution or the person producing the video evidence, in court, to exclude every possibility inconsistent with authenticity as long as the evidence is sufficient to allow a prudent person to believe the evidence is what it purports to be. Finally, it is the judge who has to determine the probative value of video evidence (United States v. Alicea-Cardoza, 1997).

\section{REFERENCES}

Ammar Yasir Ali v. The State (2013 PCr.LJ 783 (Karachi).

Asfandyar and another v. Kamran and another (2016 SCMR 2084).

Authentication. In The Webster's New 20th Century Dictionary. New York: Webster.

Azhar Mehmood alias Moodi v. The State and another (2014 P Cr. L J 1635 [Lahore]).

Bakht Munir and 2 others v. The State and another (2014 P Cr. L J 1472 [Peshawar]).

Commissioner Income Tax v. Habib Bank Limited And Anz Grindlays Bank Plc (2015 P T D 619 Supreme Court of Pakistan).

Ejaz v. The State and 10 others (2017 Y L R Note 342 [Lahore (Multan Bench)].

Forensic evidence | List of high impact articles | PPts | Journals | Videos. (n.d.). Longdom Publishing SL | Open Access Journals. Retrieved from: https://www.longdom.org/scholarly/forensic-evidence-journals-articlesppts-list-2263.html

Gregory, S., Caldwell, G., Avni, R., \& Harding, T. (2005). Video for change: A how-to guide on using video in advocacy and activism. Pluto Press (UK).

Hanif v. State (PLD 1992 Lah. 314); see also C.D Field. Law of Evidence, 5 Vols.Vol.3, $11^{\text {th }}$ edition (Law Publisher India (Pvt.) Ltd.) Page 2141).

Haq Nawaz and others v. The State and others (2000 SCMR 785).

International Journal of Computer Science \& Engineering Survey (IJCSES), 2(4).

Ishtiaq Ahmed Mirza \& others Vs. Federation of Pakistan \& others (PLD 2019 Supreme Court 675).

Kh. Ijaz Ahmad and others v. D.R.O and others (2001 Y L R 448 [Lahore]).

Khan, F. A. (2015). Forensic Science in Crime Investigation with Latest Case 
Law (First ed.). Lahore: Imran Law Book house. P.591).

Moaz Waqar and others v. The State and another (2019 Y L R 2219 [Islamabad])

Muhammad Shahid Sahil v. The State (PLD 2010 FSC 215).

Muhammad Sohail alias Samma and others v. The State and others (2019 P Cr. L J 1652 [Lahore]).

Murphy, P. (2003). Murphy on Evidence (8th ed.). Oxford University Press. P.365.

National Bank of Pakistan v. Muhammad Mobin Siddiqui (1973 PLD 107 Karachi).

National Forensic Science Technology Center®. A Simplified Guide To Digital Evidence retrieved from http://www.forensicsciencesimplified.org/ digital/faqs.html. National Forensic Science Technology Center®.

Nazim Ali v. Additional Sessions Judge and others (2016 M L D 25 [Lahore]).

Niaz-Ud-Din and another v. The State and another (2011 SCMR 725).

Pakistan Penal Code (XLV of 1860), section 29.

Shahid Zafar and 3 others v. The State (P L D 2014 Supreme Court 809).

Shakeel and 5 others v. The State (PLD 2010 Supreme Court 47).

Sher Zaman v. The State (2007 Y L R 3160 [Karachi].

Sikandar Ali Lashari v. The State and another (2016 Y L R 62 [Sindh]).

Syeda Waheeda Shah v. Election Commission of Pakistan through Chief Election Commissioner and 4 others (P L D 2013 Sindh 117).

Telecom Indicator, PTA (June, 2020) retrieved on June 15, 2020 from: https:// www.pta.gov.pk/en/telecom-indicators

The Balochistan Forensic Science Agency Act, 2015, Section 8(3).

The Code of Criminal Procedure, 1898, Section 241-A, 265-C, 510.

The Constitution of Islamic Republic of Pakistan, 1973 Articles, 4, 10-A, 189, 201 and 203GG.

The Khyber Pakhtunkhwa Forensic Science Agency Act, 2020, Section 9(3).

The Punjab Forensic Science Agency Act, 2007, Section 9(3).

The Qanun-e-Shahadat Order, 1984, Articles 59, 164.

The Sindh Forensic Science Agency Act, 2017, Section 10(3).

Tubrazy, S. J. (2015). The Discovery Of Digital Evidence and Forensic LawsTheories, Concepts and Practices ( $1^{\text {st }}$ ed.). Lahore, Pakistan: Insight Law Book.

United States v. Alicea-Cardoza, 132 F.3d 1, 4 (1st Cir. 1997).

Upadhyay. S., \& Singh, S. K. (November, 2011). Video Authentication- An Overview.

Yasir Ayyaz and others v. The State (P L D 2019 Lahore 366). 